
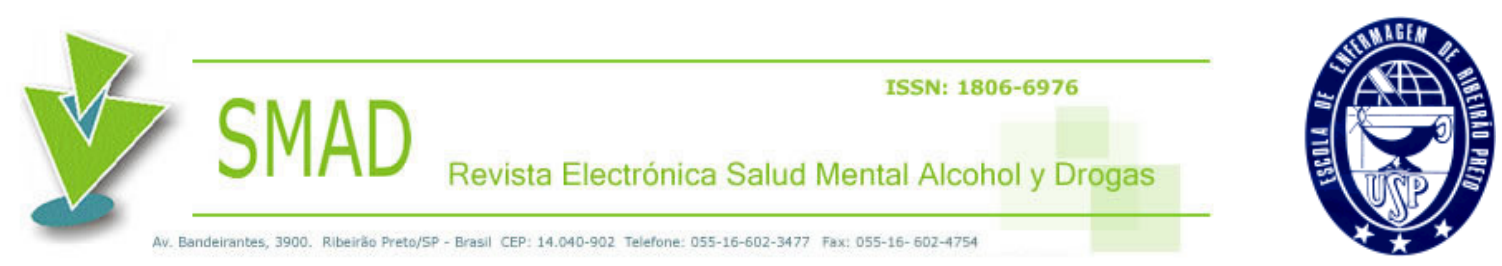

\title{
CONCEPÇÃO SOBRE DROGAS: RELATOS DOS USUÁRIOS DO CAPS-AD, DE CAMPINA GRANDE, PB*
}

\section{Julliana Keith de Sá Vieira ${ }^{1}$; Rafael Nicolau Carvalho ${ }^{2}$ Elisângela Braga de Azevedo ${ }^{3}$; Priscilla Maria de Castro Silva ${ }^{4}$; Maria de Oliveira Ferreira Filha}

Objetivou-se com este trabalho, de caráter científico, analisar a concepção dos usuários do CAPS-ad de Campina Grande, PB, acerca das drogas, avaliando suas repercussões na dependência química e o seu tratamento. Trata-se de pesquisa de abordagem qualitativa, de cunho analítico, realizada com 15 usuários do serviço. Para análise dos dados, foi utilizada a análise de discurso. O trabalho obedeceu aos pré-requisitos éticos da Resolução 196/96, do CNS, que regulamenta a pesquisa envolvendo seres humanos. Constatou-se a insipiência, por parte de alguns usuários do serviço, acerca de informações aprofundadas sobre os danos causados pelas drogas à sua saúde e, ainda, que as drogas lícitas não eram vistas como drogas. Os CAPS-ad têm papel fundamental na construção de conhecimento, e é necessário que os profissionais redefinam estratégias e práticas de acordo com essa realidade, levando o usuário a ser responsável pelo seu tratamento e reabilitação física, emocional e social.

Descritores: Usuários de Drogas; Saúde Mental; Usuários; Concepção Sobre Drogas.

\footnotetext{
* Este artigo é um recorte do trabalho de conclusão de curso: Concepção das drogas: um estudo junto aos usuários do Centro de Atenção Psicossocial - álcool e outras drogas (CAPS-ad) de Campina Grande, PB, apresentado em junho de 2008 ao Departamento de Serviço Social, do Centro de Ciências Sociais da Universidade Estadual da Paraíba (UEPB)

1-Assistente Social. E-mail: julha_21@ hotmail.com

2-Assistente Social, Mestre pela Universidade Federal da Paraíba. Professor Assistente I da Universidade Federal da Paraíba (UFPB), Preceptor da Residência Multiprofissional em Saúde da Família. E-mail: zahim1@hotmail.com

3-Enfermeira Sanitarista, Mestranda em enfermagem pela Universidade Federal da Paraíba (UFPB). Pesquisadora do Grupo de estudos e pesquisas em saúde mental comunitária.E-mail: elisaaz@ terra.com.br 4-Enfermeira, professora, especialista em Saúde Mental do Departamento de Enfermagem da Faculdade de Ciências Médicas (FCM) de Campina Grande, PB. E-mail: priscillamcs@ hotmail.com

5-Enfermeira, Doutora em Enfermagem pela Universidade Federal do Ceará; Professor Adjunto IV da Universidade Federal da Paraíba, atuação em Enfermagem Psiquiátrica. E-mail: marfilha@ hotmail.com Autor Correspondente: Elisângela Brafa de Azevedo Endereço para Correspondência: Rua Pedro Soares da Silva, 55, Bairro Itararé, CEP 58411-150, Campina Grande, PB, Brasil.

SMAD $2010 \begin{aligned} & \begin{array}{l}\text { Volume } \\ \text { Volumen }\end{array} \\ & \text { SM } 6 \begin{array}{l}\text { Numero } \\ \text { Number }\end{array}\end{aligned} 2 \begin{aligned} & \begin{array}{l}\text { Artigo } \\ \text { Artículo } \\ \text { Article }\end{array} \\ & \text { Numberista Eletrônica Saúde Mental }\end{aligned}$
}



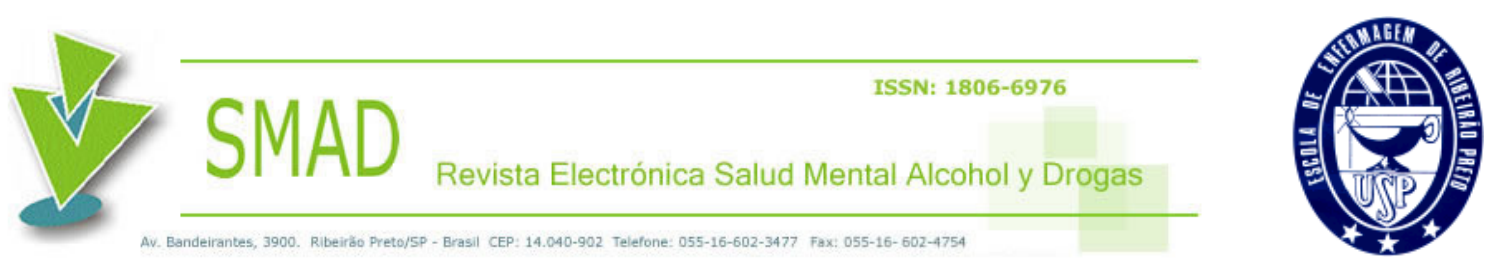

\section{Conceptions of Drugs: Reports by Users of the CAPS-ad in Campina Grande, Pernambuco, Brazil}

The purpose of this scientific study was to analyze the conceptions that users of the Psychosocial Care Centers-alcohol and drugs (CAPS-ad) in Campina Grande, Pernambuco state, have about drugs, and evaluate their repercussions on chemical dependence and its treatment. This analytical study used a qualitative approach, and was performed with 15 service users. Data analysis was performed using discourse analysis. The study complied with the ethical norms per resolution 196/96 of the National Health Council, which regulates research involving human beings. It was found that some service users were unaware about the health hazards caused by drugs and did not see licit drugs as drugs. The CAPS-ad play a fundamental role in advancing knowledge and the professionals should redefine strategies and practices according to that situation, and help patients become responsible for their own treatment and physical, emotional and social rehabilitation.

Descriptors: Drug Users; Mental Health; Users; Design on Drugs.

CONCEPCIÓN DE LAS DROGAS: RELATOS DE USUARIOS DEL CAPS-AD DE CAMPINA GRANDE, PB, BRAZIL

Con este trabajo de carácter científico, se objetivó analizar la concepción de los usuarios del CAPS-ad de Campina Grande-PB acerca de las drogas, evaluando sus repercusiones en la dependencia química y en su tratamiento. Se trata de una investigación de abordaje cualitativo, de cuño analítico, realizada con 15 usuarios del servicio. Para el análisis de los datos se utilizó el análisis de discurso. El trabajo obedeció los pre-requisitos éticos de la resolución 196/96 del CNS, que reglamenta las investigaciones que involucran al ser humano. Constatamos el desconocimiento por parte de algunos usuarios del servicio respecto de informaciones avanzadas sobre los daños causados por las drogas a su salud, y que las drogas lícitas no eran consideradas como drogas. Los CAPS-ad tienen un papel fundamental en la construcción de conocimiento, los profesionales necesitan redefinir estrategias y prácticas de acuerdo con dicha realidad para lograr que los usuarios se muestren responsables por su tratamiento y rehabilitación física, emocional y social.

Descriptores: Consumidores de Drogas; Salud Mental; Usuarios; Diseño Contra la Droga.

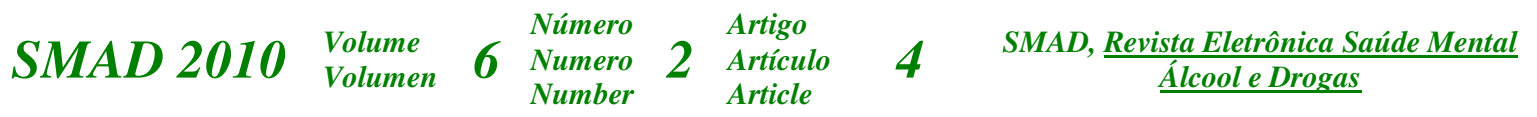



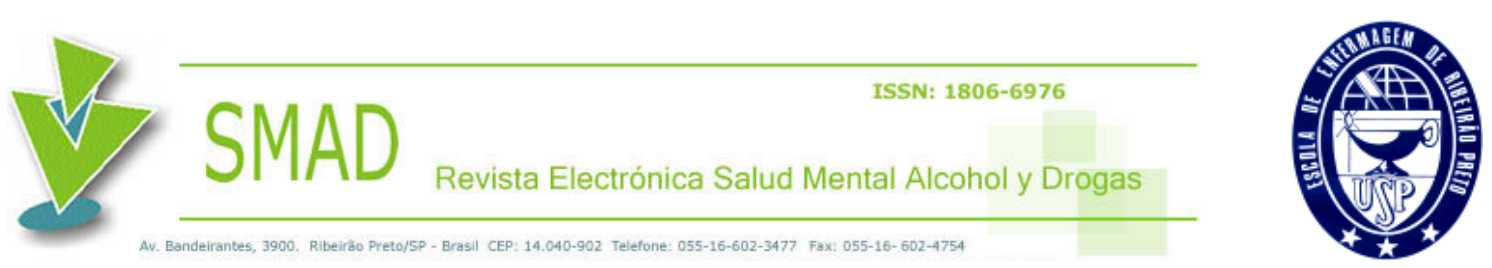

\section{Considerações Iniciais}

Para se tecer considerações iniciais, reportou-se, aqui, ao processo de Reforma Psiquiátrica no Brasil, em 1978, que, mediante a eclosão de movimentos sociais, do Movimento dos Trabalhadores em Saúde Mental (MTSM), juntamente com os trabalhadores do Movimento Sanitário, associações de familiares, entre outros, buscaram alcançar mudanças nos modelos de atenção e gestão das práticas de saúde, defendendo a saúde coletiva, a integração da rede de atendimento à saúde psiquiátrica, a equidade na oferta de serviços, a reinserção social e familiar dos pacientes e, acima de tudo, a superação da violência asilar, à qual os pacientes das clínicas psiquiátricas eram submetidos ${ }^{(1)}$.

A Reforma Psiquiátrica brasileira iniciou a luta antimanicomial inspirada na experiência italiana de desinstitucionalização, concatenada com as ideias do psiquiatra Franco Basaglia, pois esse considerava que apenas a psiquiatria não era capaz de responder pelo fenômeno complexo que é a loucura ${ }^{(2)}$. Trata-se de processo de questionamento e revisão dos vários conceitos e dispositivos jurídicos e legais, que vão desde a legislação referente à organização dos serviços até às legislações profissionais, mas, principalmente, dos conceitos e instrumentos referentes aos direitos civis e políticos dos usuários, tanto nos serviços quanto na sociedade como um todo, numa nova abordagem democrática e participativa que tem como princípios a inclusão, a solidariedade e a cidadania.

SMAD $2010 \begin{aligned} & \begin{array}{l}\text { Volume } \\ \text { Volumen }\end{array} \\ & \text { SMumero }\end{aligned} \quad \begin{aligned} & \begin{array}{l}\text { Número } \\ \text { Number } \\ \text { Numbrtigo }\end{array} \\ & \text { Articule }\end{aligned} \quad 4 \quad \begin{aligned} & \text { Arte } \\ & \text { SMAD, Revista Eletrônica Saúde Mental }\end{aligned}$ 

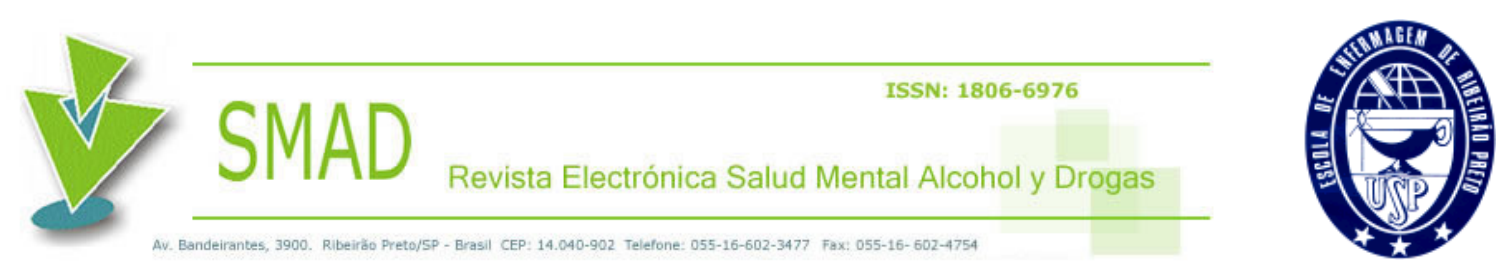

Em meio à conjuntura pela busca de ampliação e efetivação de direitos sociais na década de 80, a luta antimanicomial encontra respaldo no campo legislativo e normativo, quando foi apresentado ao Congresso Nacional, no ano 1989, o Projeto de Lei do deputado Paulo Delgado (PT/MG), propondo a regulamentação dos direitos das pessoas com transtornos mentais e a extinção progressiva dos manicômios no país. É diante da sanção e promulgação da Lei 10.216 (Lei Paulo Delgado), em 2001, que a política da saúde mental passa a ser redirecionada, ganhando maior sustentação e visibilidade ${ }^{(1)}$.

A Reforma Psiquiátrica desencadeou o processo de criação dos Centros de Atenção Psicossocial (CAPS), instituições destinadas a acolher os usuários com transtornos mentais, estimular sua integração social e familiar, apoiá-los em iniciativas de busca pela autonomia, bem como oferecer-lhes atendimento médico e psicológico, cuja característica fundamental (dos CAPS) é desenvolver estratégias para integrá-los ao ambiente social e cultural concreto $^{(3)}$.

No Brasil, foi criado o primeiro Centro de Atenção Psicossocial (CAPS), na cidade de São Paulo, em 1987, que vivenciara processo de intervenção da Secretaria Municipal de Saúde em um dos seus hospitais psiquiátricos, no município de Santos, em 1989, devido à ocorrência de maus-tratos e mortes de pacientes. Esse fato mostrou a necessidade de construção de rede de cuidados efetivos para os pacientes da psiquiatria e teve repercussão nacional como um marco no processo de Reforma Psiquiátrica brasileira ${ }^{(1)}$.

Desde então, o país passou a investir na reestruturação de uma rede de serviços substitutivos aos manicômios, composta pelos NAPS, Programa de Volta para Casa, SMAD $2010 \begin{aligned} & \begin{array}{l}\text { Volume } \\ \text { Volumen }\end{array} \\ & \text { SMumero }\end{aligned} \quad \begin{aligned} & \begin{array}{l}\text { Número } \\ \text { Number } \\ \text { Numbrtigo }\end{array} \\ & \text { Articule }\end{aligned} \quad 4 \quad \begin{aligned} & \text { Arte } \\ & \text { SMAD, Revista Eletrônica Saúde Mental }\end{aligned}$ 

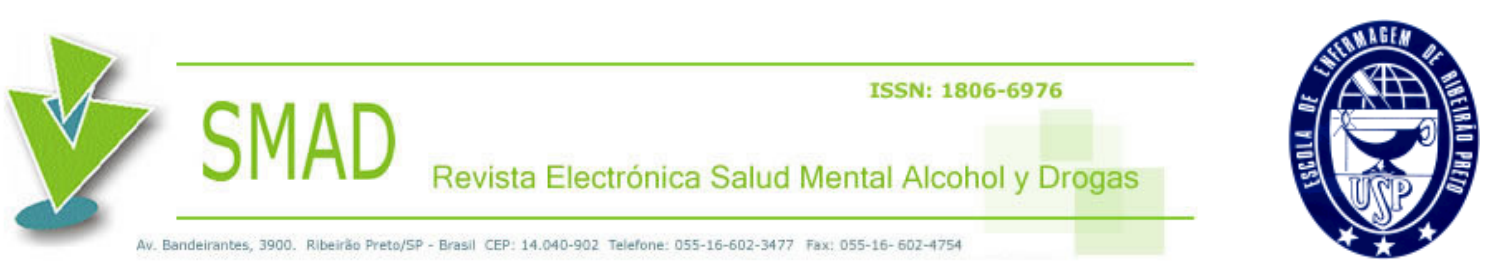

Residências Terapêuticas Hospital-dia e os CAPS, que são distribuídos como: CAPS I, CAPS II, CAPS III, CAPS i e CAPS-ad, cada qual com sua atribuição. Dentre esses, o CAPS-ad se insere como serviço especializado que atende pessoas com problemas decorrentes do uso ou abuso de álcool e outras drogas. Para o Ministério da Saúde, tal modelo se constitui em serviço gratuito, que atende usuários jovens, adultos e idosos, de ambos os sexos, com transtornos mentais e comportamentais devidos ao uso de substâncias psicoativas como álcool e outras drogas ${ }^{(4)}$.

O atendimento no CAPS-ad é realizado por equipe interdisciplinar, composta por profissionais de diversas áreas, sendo eles: assistentes sociais, enfermeiros, pedagogos, educadores físicos, psicólogos, psiquiatras, arte educadores e técnicos de enfermagem ${ }^{(4)}$. O usuário, ao ser acolhido no serviço, passa por atendimento médico, psicológico, ações do serviço social, além de outras atividades como trabalhos manuais, atividades físicas, grupos de família, coral, oficinas informativas, palestras, grupos terapêuticos, oficinas de adaptação, autocuidado, artes, momentos de lazer, alfabetização, jogos e recreação, ainda, relaxamento e música sob a perspectiva de minimizar os danos provocados pelo abuso das drogas.

Sendo assim, tomou-se como ponto de partida, para discussão deste trabalho, as mais diversas civilizações em que o uso de drogas sempre foi algo presente, uso esse associado a distintas finalidades, desde fatores culturais, como é o caso de cerimônias religiosas, até usos medicinais no tratamento de doenças. Entretanto, na contemporaneidade, o uso de drogas lícitas ou ilícitas tem se caracterizado também como problema de saúde pública,

SMAD $2010 \begin{aligned} & \begin{array}{l}\text { Volume } \\ \text { Volumen }\end{array} \\ & \text { SMumero }\end{aligned} \quad \begin{aligned} & \begin{array}{l}\text { Número } \\ \text { Number } \\ \text { Numbrtigo }\end{array} \\ & \text { Articule }\end{aligned} \quad 4 \quad \begin{aligned} & \text { Arte } \\ & \text { SMAD, Revista Eletrônica Saúde Mental }\end{aligned}$ 

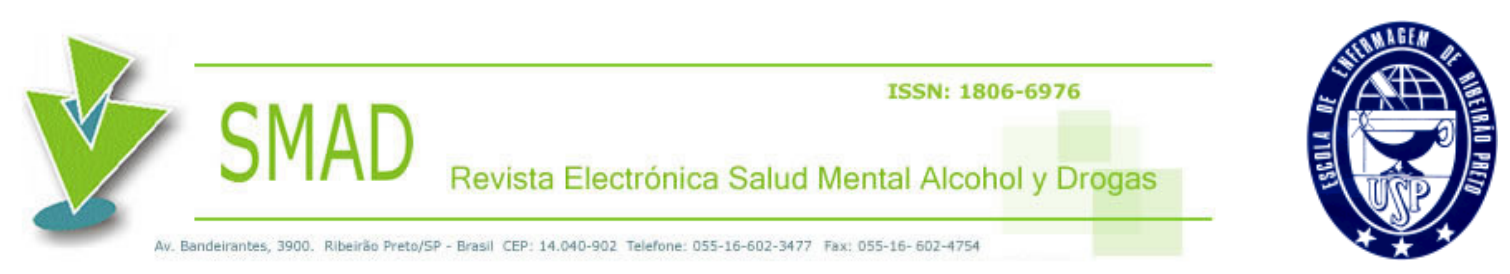

devido à sua complexidade e amplitude, atingindo pessoas de qualquer classe social, sexo, idade ou cor, como também pelas várias consequências decorrentes desse uso.

A preocupação em relação ao uso de drogas se expandiu por todo o mundo, entretanto, no Brasil, é só na virada para o século XX que se percebe a problemática das drogas como questão social, onde vários atores, dos mais diferentes setores da sociedade, passam a se ocupar do problema ${ }^{(5)}$. É importante destacar que, até o final da década de 1990, no Brasil, as pessoas que sofriam transtornos mentais, decorrentes do uso de drogas, eram internadas em clínicas psiquiátricas, sendo submetidas, junto aos doentes mentais, às mais diversas formas de violência.

O Centro de Atenção Psicossocial (CAPS), que tem, entre suas funções prestar atendimento clínico em regime de atenção diária, evitando desse modo as internações em hospitais psiquiátricos, promover a inserção social das pessoas com transtornos mentais por meio das ações intersetoriais e regular a porta de entrada da rede assistêncial em Saúde Mental na sua área de atuação ${ }^{(6)}$.

O primeiro contato dos pesquisadores com a instituição aconteceu no dia 13 de abril de 2007. A partir daí, os pesquisadores passaram a frequentar o CAPS-ad duas vezes por semana, uma pela manhã e outra à tarde. De início, a atenção foi direcionada para aprender a dinâmica do funcionamento da Instituição, bem como observar as atividades que eram realizadas no serviço. Período esse que teve a duração de seis meses. Nesse período de observação, também iniciou-se a caracterização do campo de estágio, através de dados

SMAD $2010 \begin{aligned} & \begin{array}{l}\text { Volume } \\ \text { Volumen }\end{array} \\ & \text { Solumero }\end{aligned} \quad \begin{aligned} & \begin{array}{l}\text { Número } \\ \text { Number } \\ \text { Number }\end{array} \\ & \text { Artículo } \\ & \text { Article }\end{aligned} \quad 4 \quad \begin{aligned} & \text { Artigo } \\ & \text { SMAD, Revista Eletrônica Saúde Mental }\end{aligned}$ 

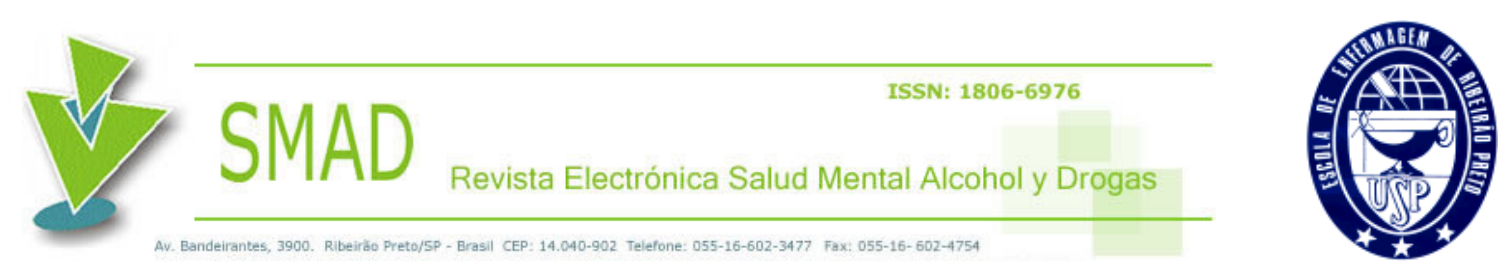

coletados na instituição e por meio de pesquisa bibliográfica, para melhor compreender a rede de saúde mental em Campina Grande e o trabalho desenvolvido no CAPS-ad.

Com a continuidade da inserção nesse serviço, um fato que chamou a atenção foi que a maioria dos usuários é dependente de drogas lícitas como álcool e fumo, sem, no entanto, considerá-los como drogas, antes, aderirem ao tratamento talvez pela dedução simplista que, por serem aceitas socialmente, não carregam o estigma das verdadeiras drogas, como assim expressam.

Dessa forma, este estudo remeteu a alguns questionamentos: em que medida a concepção de droga para os usuários compromete adesão e qualidade do tratamento? O CAPS-ad consegue provocar mudanças estruturais no universo simbólico, constituído pelos usuários sobre as drogas?

Considerando-se os avanços na saúde mental, a partir da Reforma Psiquiátrica, tem-se evidenciado mais ainda o debate sobre políticas públicas voltadas à saúde mental, principalmente em relação à questão das drogas, assim, a presente pesquisa propõe a análise sobre a concepção dos usuários do CAPS-ad, de Campina Grande, PB acerca das drogas, avaliando suas repercussões na dependência química e tratamento desses.

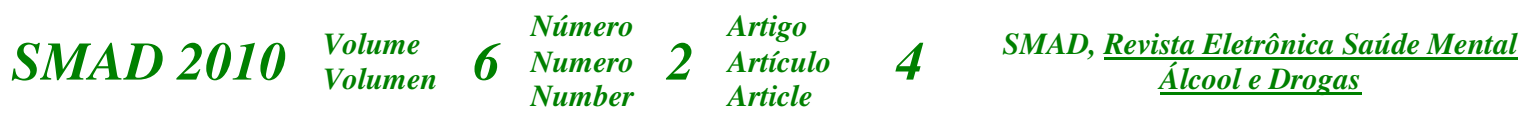



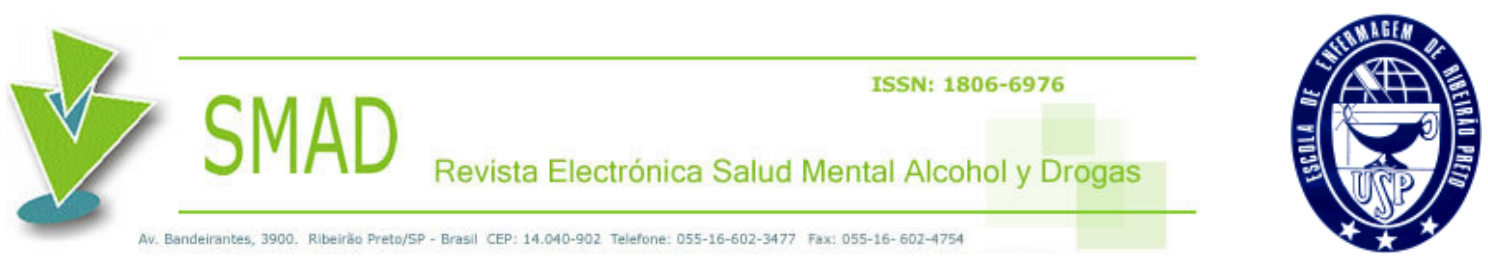

\section{Percurso Metodológico}

O presente estudo caracterizou-se como pesquisa de cunho analítico, pois essa identifica os fatores que determinam, ou que contribuem, para a ocorrência dos fenômenos ${ }^{(7)}$. Assim, foi adotada a abordagem qualitativa uma vez que essa "trabalha com universo de significados, motivos, aspirações, crenças, valores e atitudes, a que corresponde a um espaço mais profundo as relações, dos processos e dos fenômenos que não podem ser reduzidos à operacionalização de variáveis" ${ }^{,(8)}$.

Os sujeitos desta pesquisa foram os usuários do CAPS-ad. E o tipo de amostra utilizada foi a amostragem aleatória simples, onde se trabalhou, inicialmente, com o universo de pessoas que frequentaram o tratamento com mais assiduidade, definindo uma amostra de 27,8\% dos usuários, correspondendo a 15 entrevistados. Entretanto, um dos fatores de inclusão foi que os sujeitos da pesquisa tivessem idade acima de 18 anos, fossem cadastrados e acompanhados no CAPS-ad e que aceitassem participar da pesquisa.

O instrumento utilizado foi entrevista semiestruturada, com nove questões norteadoras. Assim, através das informações obtidas, as informações foram relacionadas ao seu contexto social e realizada análise crítica, onde encontraram respostas para os questionamentos, facilitando, assim, a análise mais detalhada na construção do material empírico, já que foi empregada a técnica de análise de discurso.

Nesse ínterim, a análise de discurso problematiza as evidências e explicita seu caráter ideológico, e denuncia o encobrimento das formas de dominação política nos

$$
\text { SMAD } 2010 \begin{aligned}
& \begin{array}{l}
\text { Volume } \\
\text { Volumen }
\end{array} \\
& \text { SMumero }
\end{aligned} \quad \begin{aligned}
& \begin{array}{l}
\text { Número } \\
\text { Number } \\
\text { Numbrtigo }
\end{array} \\
& \begin{array}{l}
\text { Articulo } \\
\text { Article }
\end{array}
\end{aligned} \quad \begin{aligned}
& \text { SMAD, Revista Eletrônica Saúde Mental } \\
& \underline{\text { Álcoole Drogas }}
\end{aligned}
$$


discursos. Sendo assim, a linguagem está marcada pelo conceito de social e histórico e deve ser considerada como interação inserida na relação necessária entre homem e realidade natural e social ${ }^{(9)}$.

Ainda, o referido autor ${ }^{(9)}$ apresenta o quadro epistemológico da análise de discurso, fundamentado na articulação de três regiões do conhecimento científico:

a) o materialismo histórico, como teoria das formações sociais e suas transformações;

b) a linguística, como teoria dos mecanismos sintáticos e dos processos de enunciação;

c) a teoria do discurso, como teoria da determinação histórica dos processos semânticos.

Em relação à Resolução no 196/96, do Conselho Nacional de Saúde, o presente projeto foi submetido à análise do Comitê de Ética em Pesquisa da UEPB e, assim, o entrevistador pôde prestar os imprescindíveis esclarecimentos aos entrevistados acerca do teor da pesquisa, de modo que esses puderam firmar o termo de consentimento livre e esclarecido, ficando uma via com o sujeito da pesquisa e outra arquivada pelos pesquisadores.

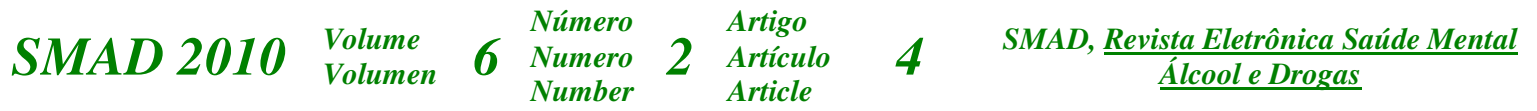



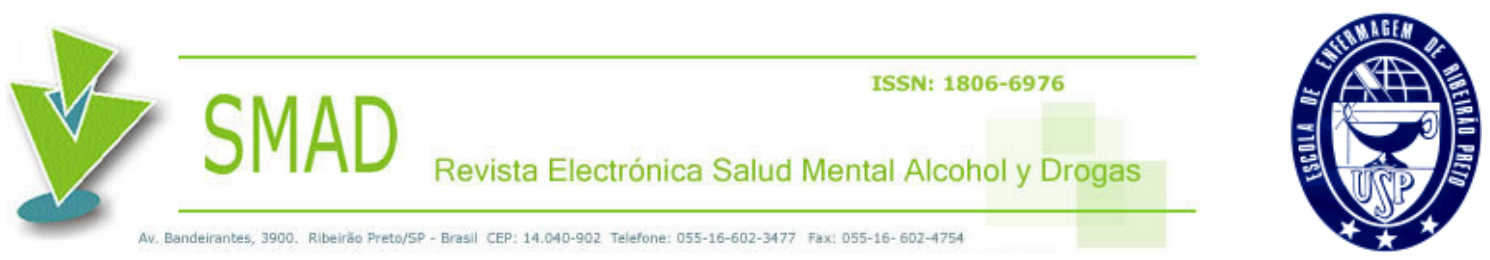

\section{Análise dos Resultados e Discussões}

$\mathrm{Na}$ análise do material empírico, pode-se perceber que o conceito que os usuários do CAPS-ad têm sobre as drogas surgem de opiniões diversificadas, porém, todos os entrevistados classificam as drogas como algo negativo, desorganizador de suas vidas, acarretando o afastamento de familiares, da religião, de amigos e perda de bens materiais. Esses fatos podem ser observados nas falas, a seguir.

Droga, pra mim hoje em dia, realmente é como o nome diz é uma droga, nada, eu já abominei da minha vida. Espero que não tenha nenhuma recaída e não recomendo pra ninguém, porque eu sofri muito, eu cheguei ao fundo do poço; destruí tudo que eu tinha, perdi meus amigos, tava saído do álbum de família, não perdi meu esposo, porque realmente ele me ama muito, é tanto que ele tá comigo até agora, ele acreditou em mim, apostou a última ficha (ENTREVISTADO 1).

Droga é a destruição do mundo, destrói todo mundo que consome ela, começa aos pouquinhos depois vai se aprofundando, de repente tá num hospital, num cemitério ou numa cadeia. Ou perca de familiar, ou perca danos e objetos, até a saúde (ENTREVISTADO 4).

Consideram como dependentes aqueles que apresentam os comportamentos dos drogadictos, pois eles são movidos pelo desejo poderoso, compulsivo, de utilizar uma substância psicoativa, procura que invade, progressivamente, toda a sua existência. Existência essa que afeta família, trabalho, enfim, toda sua teia social. Tais autores consideram a dependência uma patologia que tende a se cronificar ${ }^{(10)}$.

Um fato que chama a atenção nos depoimentos dos entrevistados(as), sobre sua concepção acerca das drogas, antes de frequentarem o tratamento no CAPS-ad, é que a maioria não considerava álcool e cigarro como drogas, mas apenas maconha, crack (mais

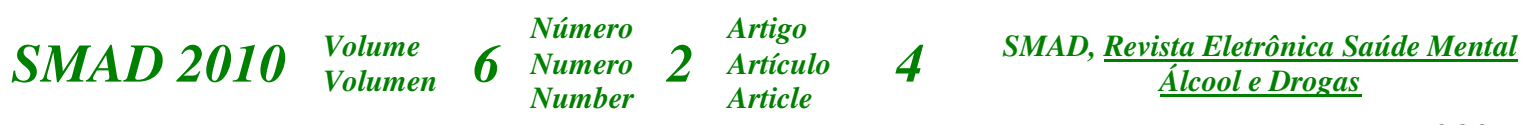



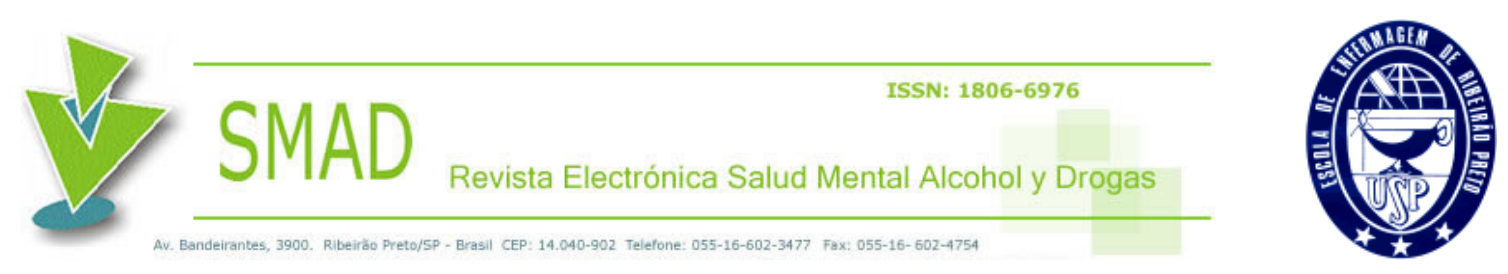

citadas) etc.

[...] droga pra mim era isso que o povo fuma, maconha, esses outros negócios que eu via o povo falar; crack eu vi falar já aqui dentro, nunca tinha ouvido falar não. Pra mim droga era só essas coisas, álcool e cigarro não era não (ENTREVISTADO 2).

Eu não conseguia mais estudar por causa da droga que foi o álcool. Achava que fazia bem, me divertia, porque eu era viciado, bebia desde os 6 anos de idade. E não sabia que álcool e cigarro eram droga, só fui saber em 1990, quando entrei nos alcoólicos anônimos (ENTREVISTADO 9).

Álcool eu não considerava, só a maconha. Eu comecei a usar o crack porque eu usava e não conseguia mais parar, porque quanto mais usa quer mais, quer mais (ENTREVISTADO 11).

Sobre esse fato, pode-se deduzir, e isso foi verificado pela observação participante nas diversas atividades acompanhadas, junto aos usuários, que as drogas, muitas delas, entraram na vida dos entrevistados pela "porta da frente", como relatam, nos espaços sociais, como clubes, festas, comemorações e no próprio ambiente familiar, sendo que seu malefício é percebido apenas com a instalação de dependência física e/ou psíquica da substância, desorganizando o tecido da sua vida social. A não compreensão do álcool como droga evidencia esse fácil acesso, dificultando a aceitação da doença (dependência), bem como do seu devido tratamento. Vale destacar que o álcool, apesar de ter seu uso legalizado, também é considerado uma droga psicoativa.

De acordo com esse autor, seu efeito no cérebro é complexo, mas, de modo geral, é classificado como depressor do sistema nervoso central. Após beber aparecem efeitos estimulantes como euforia e desinibição, e, à medida que se consome a bebida, passam a existir os efeitos depressores, como falta de coordenação motora, descontrole e sono. Quando o consumo é exagerado o efeito depressor pode levar ao coma ${ }^{(11)}$.

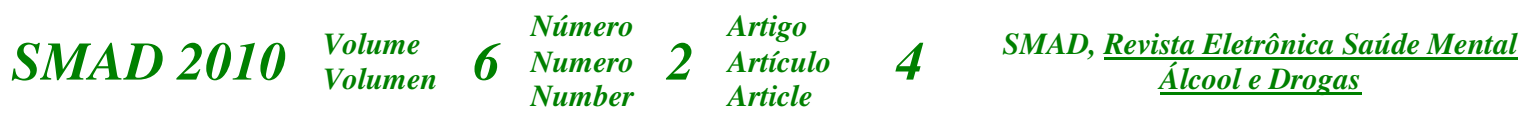



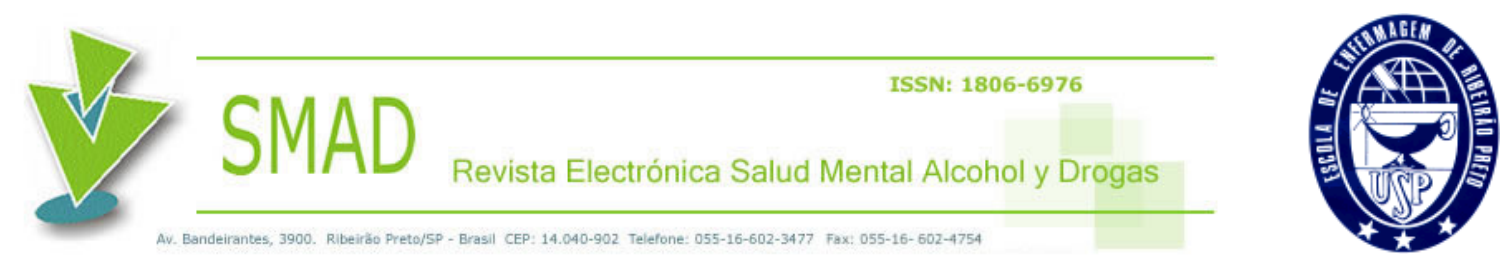

Indagados se sua concepção sobre as drogas continua a mesma, após o tratamento no CAPS-ad, os(as) entrevistados(as) foram enfáticos ao afirmar que mudaram a forma de ver as drogas, pois, antes, acreditavam que essas serviam como diversão ou refúgio para os problemas, baixa autoestima, assim como apontam nos discursos seguintes.

\begin{abstract}
Não! Porque eu tive mais um entendimento, que pra você se divertir ou qualquer coisa que você vá fazer não precisa de droga, porque isso aí é besteira. A gente pensa. Você primeiro fuma por alegria, depois você fuma por tristeza, ah eu tô triste vou fumar, aí vou pra uma festa vou fumar. No dia em que minha mãe morreu ou alguém morreu eu tô deprimida eu vou fumar, vou fumar pra me dá mais coragem, tudo isso é ilusão. Por isso que eu tenho essa concepção que droga realmente é uma droga (ENTREVISTADO 1).
\end{abstract}

Não. Porque afetou muito minha vida, tanto no trabalho, como na escola, como com a pessoa com quem eu convivo, família também, minha mãe que eu perdi ela porque ela ficou com desgosto de mim, antigamente eu não usava e comecei a usar, nisso ela faleceu de desgosto, eu ficava bêbada, eu não estava gostando muito de mim, não me ajeitava mais e ela via isso e ficava triste. [Sua concepção sobre as drogas mudou depois que você veio para o CAPS?] mudou muito, muito mesmo, me ajudou muito; os funcionários, os psicólogos, me ajudaram muito e ainda estão me ajudando, [...] a técnica, o doutor, os remédios tudo isso tá me ajudando (ENTREVISTADO 3.)

Não. Porque eu sei que a gente aqui a gente esquece das droga. Usava (álcool) porque entrava em festa acompanhado dos amigo e eles chamavam pra beber, $e$ desse fim de semana fiquei alcoólatra mesmo. E eu acho que pra o cara se divertir não carece da droga não, a gente se diverte conversando com os amigos, brincando de dominó, tem vários tipos de divertimento fora das drogas (ENTREVISTADO 7).

Pode-se verificar a relevância do trabalho educativo realizado com os usuários, na medida em que se consegue ressignificar a concepção dos mesmos sobre as drogas, a mudança de paradigma remete ao reconhecimento de sua situação de vida, dos motivos explícitos e implícitos para seu consumo, fazendo com que, de posse dessa concepção, os usuários se percebam como responsáveis pelo seu tratamento e reabilitação emocional, social e física.

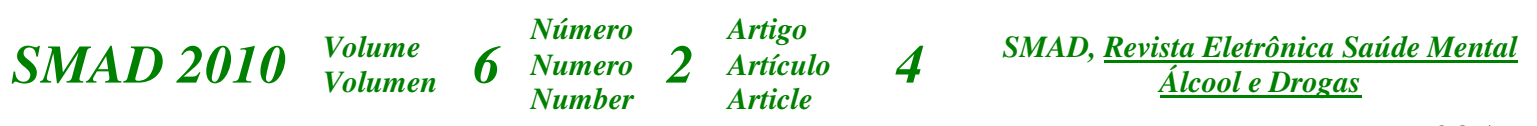



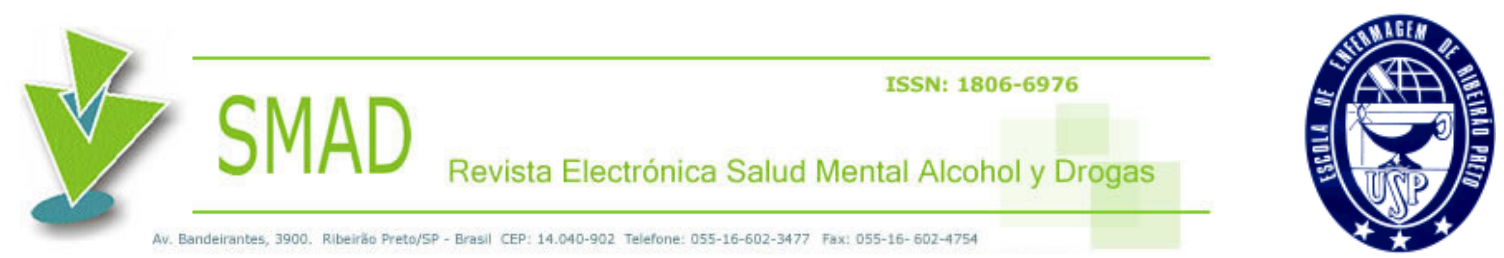

Contemplando a ideia supracitada, nessas pesquisas os distúrbios no uso de drogas psicoativas estão associados ao uso de drogas pelos indivíduos com baixa autoestima, sintomas depressivos, eventos de vida estressantes, baixa coesão familiar e ligação com amigos que consomem drogas ${ }^{(12)}$.

Quando questionados sobre o que puderam conhecer a respeito das drogas, durante o tratamento, a questão dos danos causados à saúde foi muito citada, e todos os entrevistados mencionaram que, se soubessem desses males, certamente não a teriam usado.

\begin{abstract}
Que as drogas afeta várias parte do corpo, saúde, o corpo inteiro, às vezes os rins, os pulmão, às vezes o cérebro. O cara pode ter emprego bom, de repente perder aquele emprego devido às drogas, pode ter a esposa e os filhos e perder por causa das drogas, pode ter casas boas, mais casas, carro bom, e vender tudo pra... e perder tudo (ENTREVISTADO .4).

Conheci muitas coisa, já teve palestras com outras pessoas sobre a droga, é um sistema que não tem como você explicar sobre os benefício dela e o mal, que no caso é o mal que há. No caso meu não quero mais isso pra minha vida e vou me ajeitar porque do jeito que tava não pode mais ficar, tava perdendo tudo e agora tá mudando (ENTREVISTADO 13).
\end{abstract}

As concepções emitidas pelo conjunto de entrevistados revelam que esses consideram relevantes ter informações, pois alguns passam a usar drogas por falta de informação. A questão do preconceito foi bastante mencionada tanto perante a sociedade como até entre eles também, devido ao fato de uns usarem drogas lícitas e outros fazerem uso de drogas ilícitas. Um dos entrevistados diz que ter informação é importante até para se tomar a decisão se deve ou não fazer uso das drogas.

Acho. Porque se tem pelo menos que ouvir as informações se salvar já é muita coisa, porque muitos entram por falta de informação, como muitos jovens que não têm o conhecimento; tem gente que é mais fácil criticar por não conhecer as informações, aí você tendo as informações você pode ajudar. Quem eu criticava,

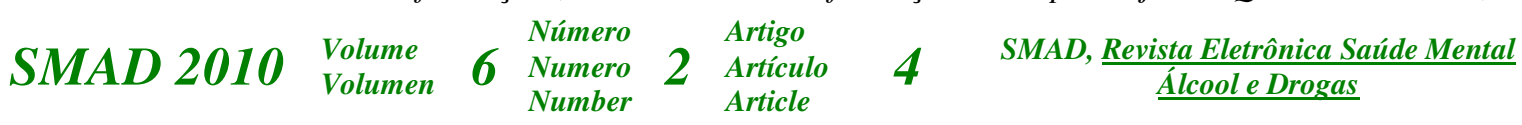



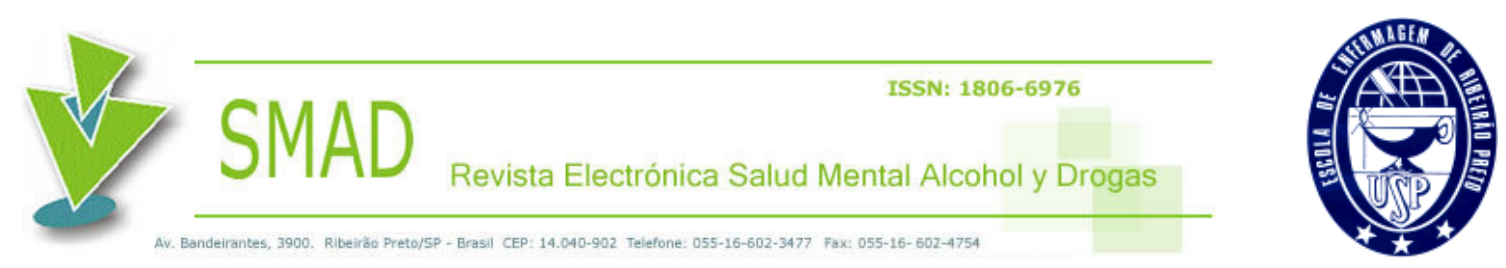

hoje eu ajudo, quem me criticava hoje me ajuda; por ter o conhecimento. Então você acha importante tanto para as pessoas que usam, como pra quem está ao redor (ENTREVISTADO 1).

É. Porque conforme você conhecendo ela, você vai conhecer o mal que ela faz, você sabendo o mal que ela faz só vai se for idiota. Que aí onde tá você buscar dentro de si aquela força de vontade, que ajuda você tem, com psicólogo, com tudo, de familiares, de amigos. [...] Mas você sabendo daquele mal ali... você vai pisar num xiquexique com um mói de espinho, de pé descalço? Só se for besta. A informação é importante. Se você saber o que é, se conscientizar, tudo direitinho, saber o que é tudinho, e botar na cabeça, ter aquela força de vontade você não entra. De maneira nenhuma, nem por ensinação de amigos, nem por influência, nem de nada. (Ter informação é importante pra você decidir se vai entrar ou não?). Sim, e também fortalecer o apoio que seus parceiros estão lhe dando, ali você fortalece mais; como se fosse o espinafre de Popeye, pra fortalecer, pra você botar na cabeça e dizer: realmente é! (Você já sofreu algum preconceito?). Muitos! (Você acha que se as pessoas tivessem informações sobre as drogas, você sofreria esse preconceito?). Não, porque saberia que é uma doença, um vício. Não iriam fazer o preconceito, tentariam ajudar (ENTREVISTADO 5).

Eu acho muito importante, porque a gente vê muito em televisão, mas a gente falando pessoalmente tá vendo que é verdade mesmo. Acho diferente porque por televisão eu posso pensar que é um teatro que a pessoa tá falando, mas ouvindo assim a pessoa falando você vê que é verdade, a gente tá no CAPS e a moça falou essa coisa! No meu modo de entender, na televisão é como um teatro que as pessoas tá mostrando como pode acontecer, mas não passou isso, não é realidade, acho que é apenas mais um teatro (ENTREVISTADO 7).

Acho muito importante, porque eu procuro me afastar. Não usaria se soubesse dos efeitos, eu comecei a usar na inocência, desde 1954, só vim saber que era droga quando entrei em alcoólicos anônimos, foi quando eu vim compreender, entender o que era o álcool, que era uma droga igual as outras. Eu descriminava quem usava maconha, crack, cocaína, mas agora não descrimino mais porque vi que as drogas são tudo igual, embora nunca ter usado, maconha, crack, cocaína, LDS, somente o álcool, a cachaça (ENTREVISTADO 9).

Com certeza. Porque se você tiver a informação fica mais fácil de sair se você entrar, e você tendo a informação fica mais fácil de você não querer entrar. Sem a informação você vai ter a curiosidade, mas, se você tiver a informação não vai ter a curiosidade de querer saber como é que funciona. Se tivesse a informação que eu tenho hoje, no meu caso o crack eu nunca teria usado. E posso passar informação pra outras pessoas, e também do que eu passei, agora eu tenho o que dizer, antes eu não tinha, achava aquilo o máximo, ficava me sentindo o máximo, hoje em dia a gente vê que é totalmente diferente daquilo, é o oposto daquilo que a gente pensava (ENTREVISTADO 13).

É visível, nos relatos acima, certo preconceito quanto ao tipo de droga utilizada

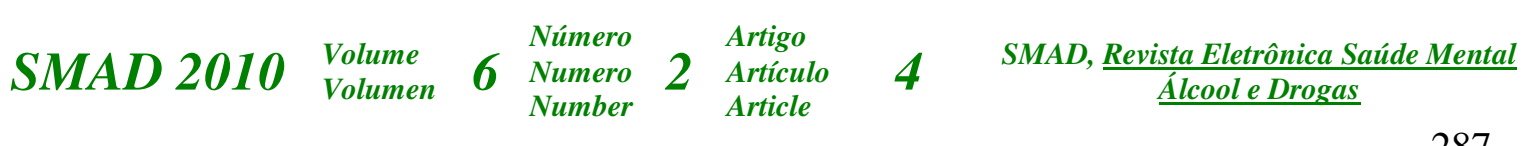



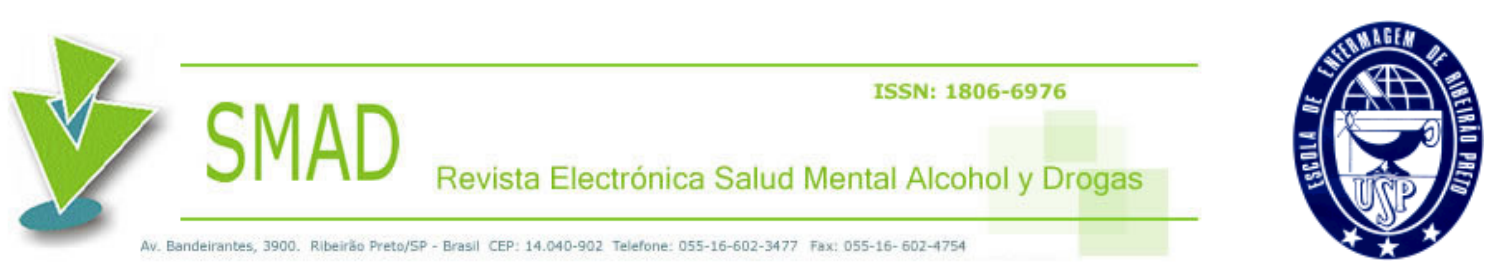

(licitas e ilícitas) o que expressa a própria forma como a sociedade estruturou historicamente seu tratamento às drogas, tornando as drogas ilícitas em caso de polícia, marginalizado e/ou estigmatizando quem as consome. Mais uma vez se vê a importância da informação, o que leva a induzir que, mesmo com uma política nacional de álcool e outras drogas, as ações educativas são insuficientes ou insatisfatórias na medida em que não conseguem penetrar na vida social dos sujeitos.

Contextualizando a ideia, pode-se dizer que o tratamento do dependente de substâncias psicoativas é bastante complexo e os estudos sobre os tratamentos para a população adulta mostra que tratar é melhor que não tratar, mas não existe nenhum tratamento mais efetivo até o momento. A recaída, o desejo pela droga, representada pela fase de fissura, o pouco envolvimento nas tarefas escolares ou no trabalho, o lazer insatisfatório, a polidependência, o início de uso do álcool muito cedo na vida, as alterações de comportamento e o envolvimento criminal são fatores que contribuem para tornar o tratamento menos efetivo ${ }^{(13)}$.

Ao se analisar a opinião dos usuários sobre a repercussão que o seu entendimento atual sobre as drogas tem no seu tratamento, a maioria relatou que deixou de usar drogas, ou pelo menos reduziu bastante o consumo, e que estando no CAPS-ad está afastado das drogas, evitando assim o fácil acesso a essas. Foi citado também o amor próprio e a força de vontade para continuar na abstinência e o medo de recaída.

Sim, foi fundamental pra conhecer o mal que ele me fez e faz, tanto a mim socialmente, mentalmente, fisicamente, psicologicamente, tudo! Hoje em dia eu estou voltando a ser o que eu era, porque se você me visse há alguns anos

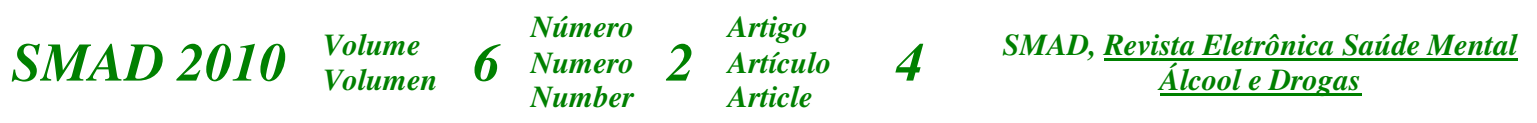


atrás... Ave Maria! Eu tinha medo, eu tive medo de mim, porque eu tentei suicídio, porque eu vendi tudo e chegou ao ponto de eu não ter mais onde eu arrumar dinheiro pra me drogar, ao não ser que eu roubasse. E isso eu não queria, mas assim mesmo ainda roubei muito do meu marido, que também é roubo, porque não tem diferença nenhuma de você pegar uma coisa que não é sua de alguém de casa ou de alguém na rua, é o mesmo roubo. E por isso que era matar ele e depois me matar, meu pensamento era esse; foi quando eu tive uma crise, uma depressão, e pedi discernimento a Jesus e ele me mostrou o meu marido, e foi aí que eu falei com ele e ele disse: eu já sabia há muito tempo só que pra mim lhe ajudar você tem que querer, você não tava querendo. Dois dias depois, que foi final de semana, ele me trouxe pra cá, aqui estou, não faltei nenhum dia, nem consumi mais droga a não ser o tabaco, o cigarro e nem quero mais consumir, não critico quem usa, só não quero pra mim; se eu puder ajudar tudo bem, mas também criticar eu não critico não porque também eu sei que a primeira vez você prova por curiosidade, da segunda, então, você já se torna viciado. E o crack ele veio pra destruir realmente, porque as outras drogas, às vezes, dependendo do psicológico de cada um você pode ter um certo controle, mas o crack não, você não se controla, você não tem controle de forma alguma, é meu ponto de vista (ENTREVISTADO 1).

Ajuda e muito. Vindo pra cá todo dia saí do meio da tentação de lá, que lá no Pedregal é muita tentação. Se eu tivesse em casa antes eu tava fumando, hoje se eu ficar em casa eu não fumo (ENTREVISTADO 10).

No conjunto das falas, ora analisadas, pode-se identificar alguns eixos norteadores de análises para essa pesquisa. Primeiro, a importância da concepção das drogas para os usuários atendidos, na medida em que essas impressões podem refletir em sua adesão ao tratamento, dificultando ou facilitando o processo, implicando que mexer nesse universo de significados exige competência técnica e teórica para respeitar os valores dos usuários, incluídos num processo participativo de construção de novos conceitos para a busca de sua ressignificação. Segundo, a valorização das práticas educativas como espaços pedagógicos e democráticos para o processo de aprendizagem e de construção de conhecimentos, acerca das drogas, como forte fator de adesão ao tratamento e o reconhecimentos do abuso das drogas visto como algo prejudicial às suas vidas. Terceiro, o reconhecimento do espaço institucional do CAPS-ad como ambiente de apoio e aprendizagem, onde muitas vezes é

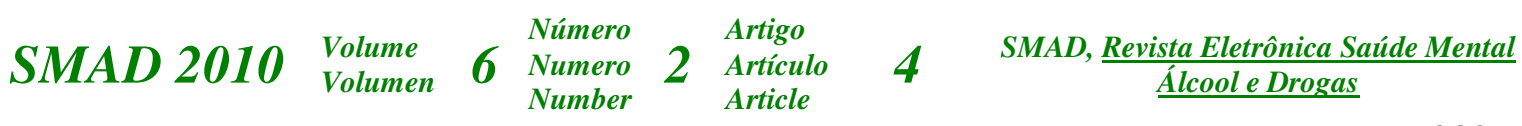



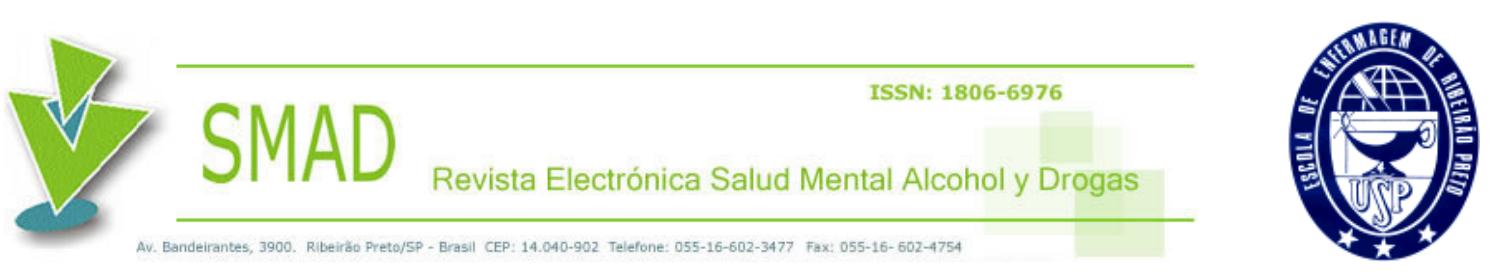

visto como alternativa de se manter longe do ambiente propício ao uso das drogas.

Diante dessas análises, a pesquisa cumpre seu objetivo principal, reafirmando a relevância e trazendo novos elementos para a prática institucional e profissional dos diversos profissionais, inseridos no atendimento desses usuários, bem como o conhecimento de suas vidas, seus valores e concepções, como substrato material e imaterial na busca da construção de novos conhecimentos acerca dessa problemática que aflige a sociedade e se torna problema de saúde pública, na medida em que grande parcela da população está sujeita ao consumo abusivo de drogas.

\section{Considerações Finais}

O uso de drogas é datado de épocas antiquíssimas. Foram utilizadas das mais distintas maneiras, encaradas pela sociedade como algo natural, ou comum, até os dias em que se transformaram em caso de polícia e/ou questão de saúde pública. Portanto, a forma como o uso de drogas tem sido visto, atualmente, difere de épocas anteriores, onde a saúde pública brasileira não vinha se ocupando devidamente com o grave problema da prevenção e tratamento de transtornos associados ao consumo de álcool e outras drogas.

Pela complexidade do problema, o Estado se mostrou ausente, e as alternativas de atenção eram baseadas em práticas médicas ou psiquiátricas, tendo como principal objetivo a ser alcançado a abstinência. As ofertas de tratamento eram inspiradas em modelos de exclusão/separação dos usuários do convívio social. Inúmeros são os comprometimentos

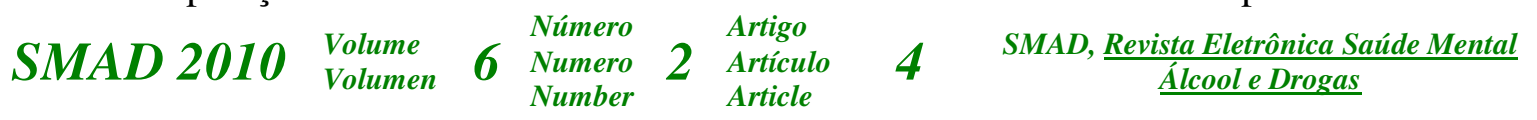



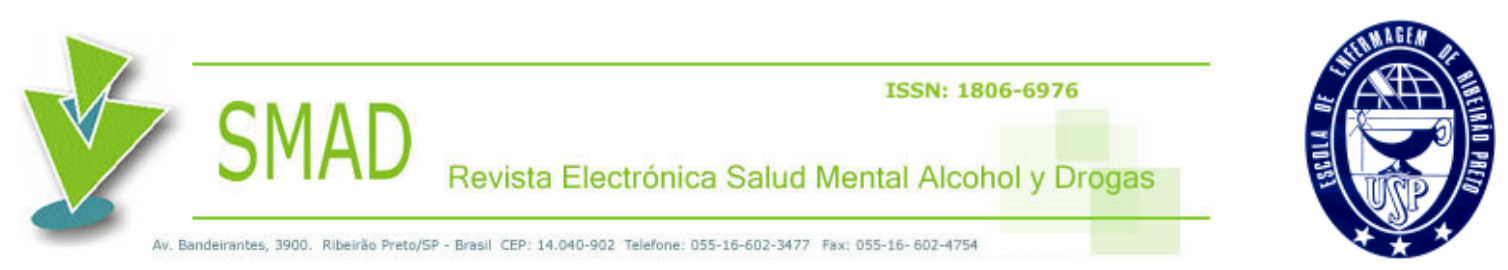

individuais e sociais relacionados às drogas, o que permite que, com frequência, se fale na problemática das drogas.

Houve demora do poder público em reconhecer o uso/abuso das drogas e problemas associados como questão de saúde. Somente a partir de 2002, o Ministério da Saúde publicou portarias definindo, de modo consciente, as diretrizes de política pública de atenção voltada para o usuário de álcool e outras drogas.

Como dispositivos estratégicos, criados pelo Ministério da Saúde, pode-se destacar os Centros de Atenção Psicossocial (CAPS-ad), nos quais, como forma de tratamento, são propostas a reinserção social, melhor qualidade de vida por programas de redução de danos e apoio familiar no tratamento dos usuários.

As relações estabelecidas com as drogas se tornam cada vez mais complexas, e essas passaram a ser associadas a diversos problemas de ordem pessoal e social. Presencia-se grande crescimento da oferta, como também do consumo das drogas, propiciando a estruturação de mercado ilegal e lucrativo, distribuição e venda das drogas, sustentado muitas vezes pela utilização de práticas violentas.

O uso das drogas leva à perda de empregos e bens materiais, rupturas familiares, afastamento da religião, instabilidade financeira, abuso físico e psicológico no sentido de que alguns dos usuários chegam a um grau de depressão tão forte que pensam até em suicídio.

Ao longo desta pesquisa, pôde-se constatar que os usuários do CAPS-ad não tinham informações aprofundadas sobre os danos que as drogas causam à saúde e à convivência. E

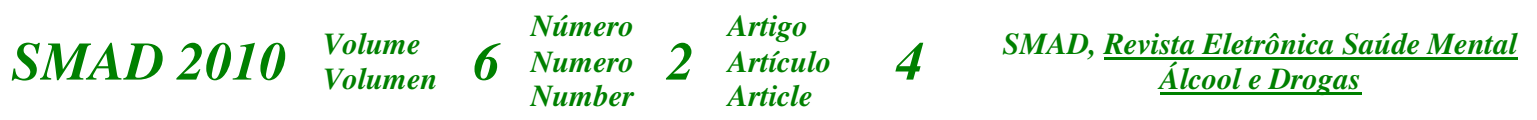



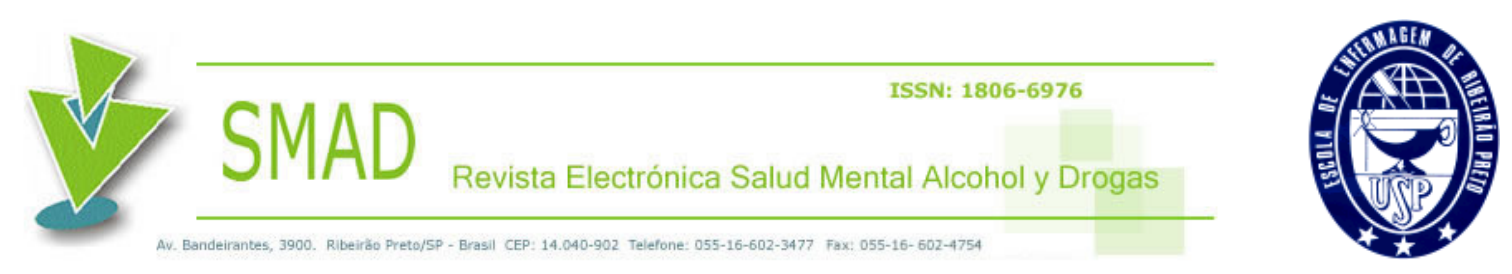

que as drogas lícitas, na grande maioria das vezes, não eram ou não são vistas como drogas, isso se deve ao fato como foi construído histórica e culturalmente o imaginário social a respeito das drogas, ou seja, cigarro e álcool podem ser utilizados livremente, portanto, não trazem nenhuma consequência maior ao indivíduo (isso está tão fortemente construído que até alguns dos usuários que frequentam o CAPS ainda não se reconhecem como usuários de drogas, mesmo essas sendo licitas), enquanto que as drogas ilícitas, tidas como casos de polícia, levam seus usuários à prisão e à discriminação tanto no meio social, como também pelos usuários de drogas lícitas.

O preconceito existe em meio aos usuários do CAPS-ad pelo não reconhecimento que, apesar de lícitas, também são drogas. Enquanto que a sociedade também não tem o conhecimento de que a dependência química é uma doença, e, portanto, acaba estigmatizando e excluindo o usuário de drogas. Dentre outros fatores importantes, percebe-se que a baixa autoestima, dentre outros fatores psicológicos, como, por exemplo, a depressão, pode fazer com que os usuários de drogas cheguem ao ponto de querer ou até tentar suicídio, algo que foi bastante citado pelos usuários e que pôde ser constatado na observação participante. Destarte, a religião pode surgir como busca de tratamento alternativo, quando os tratamentos formais não oferecem respostas imediatas.

A informação, sob a perspectiva dos autores, é algo de fundamental relevância para que essas pessoas possam entender de fato que as drogas trazem inúmeros maleficios tanto para saúde quanto para a vida como um todo. Essas informações devem ser mais bem esmiuçadas, e não apenas anunciadas em propagandas de forma rápida, como aquelas

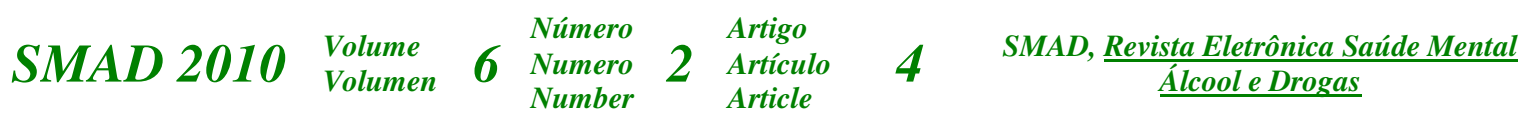



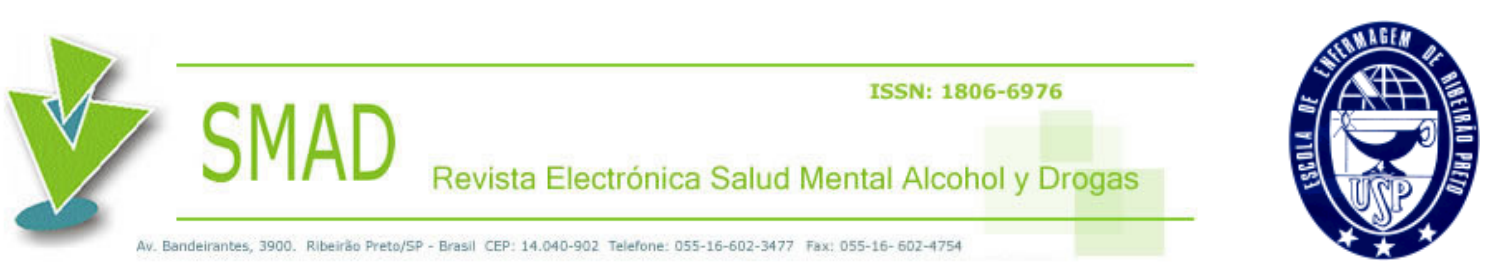

conhecidas campanhas: “drogas, não use!”, "droga mata”.

Acredita-se que os meios de divulgação de informações sobre as drogas ainda estão bastante fragilizados. As pessoas devem conhecer a fundo todas as implicações que as drogas podem trazer às suas vidas, para que, assim, possam escolher de forma consciente se querem ou não fazer uso das mesmas.

E o CAPS-ad tem papel fundamental nesse processo de construção de conhecimento. Sendo assim, cabe aos profissionais que atuam no CAPS-ad buscarem redefinição de estratégias e práticas, de acordo com essa realidade, já que o trabalho educativo, realizado com os usuários, na medida em que consegue ressignificar a concepção dos mesmos sobre as drogas, a mudança de paradigma (droga para não droga) remete ao reconhecimento de sua situação de vida, dos motivos explícitos e implícitos para seu consumo, fazendo com que, de posse dessa concepção, os usuários se percebam como responsáveis pelo seu tratamento e reabilitação emocional, social e física.

Por fim, pode-se colocar que as experiências vividas junto ao CAPS-ad e usuários foram de extrema importância para este estudo e, principalmente, para a formação profissional dos autores. Almeja-se, aqui, que este trabalho possa contribuir para a identificação das dificuldades e limites encontrados pelos usuários do CAPS-ad, no que tange ao entendimento sobre as drogas a fim de se informarem mais a respeito, visando, consequentemente, melhor adesão ao tratamento, bem como a socialização dessas informações aos que os rodeiam, para que consigam efetivar seus direitos de cidadãos, buscando sua inserção social.

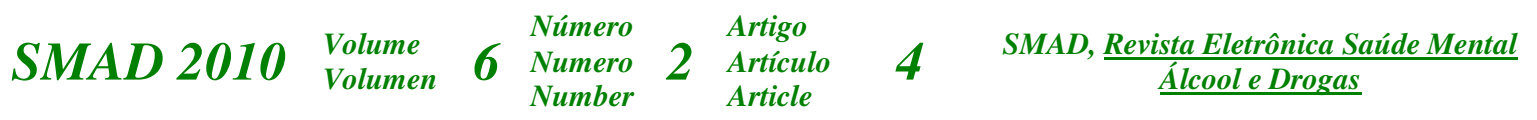




\section{Referências}

1. Ministério da Saúde (BR). Secretaria de Atenção à Saúde. DAPE. Coordenação Geral de Saúde Mental. Reforma psiquiátrica e política de saúde mental no Brasil. Documento apresentado à Conferência Regional de Reforma dos Serviços de Saúde Mental: 15 anos depois de Caracas. OPAS. Brasília; 2005.

2. Castilho W. O Trabalho é a Terapia. [acesso em: 18 maio 2007]. Disponível em: http://www.agencia.fapesp.br/materia/6650/entrevistas/o-trabalho-e-a-terapia.htm.

3. Marchi VA Busca da Integralidade nas Ações dos Profissionais de Saúde Mental: um desafio cotidiano. [Dissertação de Mestrado]. Florianópolis: Universidade Federal de Santa Catarina; 2005.

4. Ministério da Saúde (BR). Secretaria de Atenção à Saúde. DAPE. Saúde Mental no SUS: Os Centros de Atenção Psicossocial. Brasília: Ministério da Saúde; 2004.

5.Adiala JC. A criminalização dos entorpecentes. Rio de Janeiro: Fundação Casa Rui Barbosa: Papéis avulsos, crime e castigo; 1986

6. Delgado ACG, Mello M, Mello A Kohn R, Reforma Psiquiátrica e política de Saúde Mental no Brasil. Epidemiologia da Saúde Mental no Brasil. Porto Alegre: Artmed; 2007.

7. Gil AC. Métodos e Técnicas de Pesquisa. 4.ed. São Paulo: Atlas; 1994.

SMAD $2010 \begin{aligned} & \begin{array}{l}\text { Volume } \\ \text { Volumen }\end{array} \\ & \text { SMúmero }\end{aligned} \quad \begin{aligned} & \begin{array}{l}\text { Número } \\ \text { Number }\end{array} \\ & \text { Nurtigo }\end{aligned} \begin{aligned} & \begin{array}{l}\text { Artículo } \\ \text { Article }\end{array} \\ & \text { SMAD, Revista Eletrônica Saúde Mental }\end{aligned}$ 
8. Minayo MCS. Pesquisa Social Teoria Método e Criatividade. 23.ed. Petrópolis: Vozes; 2004.

9. Orlandi EP. A linguagem e seu funcionamento: as formas do discurso. Campinas: Ed. Pontes; 1987.

10. Laqueille X, Uribé M, Olié JP. Aspects cliniques actuels des toxicomanies. Rev Practic. 1995; 45(11):1359-63.

11. Bonalume R Neto. Loucuras Dentro da Lei. Rev Galileu. 3.ed. São Paulo: Globo; 2003.

12. Hoffmann J, Cerboneb FG. Parental substance use disorder and the risk of adolescent drug abuse: an event history analysis. Drug Alcohol Depend. 2002;66(3):255-64.

13. Marques ACPR, Cruz MS. O adolescente e o uso de drogas. Rev Bras Psiquiatr. 2000; 22, supl. 2:32-6.

Recebido em: 15/11/2009

Aprovado em: 12/04/2010

\section{Como citar este artigo:}

Vieira JKS, Carvalho RN, Azevedo EB, Silva PMC, Ferreira Filha MO. Concepção das drogas: Relatos de usuários do CAPS-ad de Campina Grande, PB. SMAD, Rev. Eletrônica Saúde Mental Álcool Drog. (Ed. port.) [Internet]. 2010 [acesso em: dia mês abreviado com ponto ano] ; 6(2):274-95. Disponível em: Endereço Eletrônico Visitado.

SMAD $2010 \begin{aligned} & \text { Volume } \\ & \text { Volumen }\end{aligned} \quad 6 \begin{aligned} & \begin{array}{l}\text { Número } \\ \text { Numero } \\ \text { Number }\end{array} \\ & \text { Sulticule }\end{aligned} \quad \begin{aligned} & \begin{array}{l}\text { Artigo } \\ \text { Artículo } \\ \text { Article }\end{array} \\ & \text { SMAD, Revista Eletrônica Saúde Mental }\end{aligned}$ 